\title{
Managing Supply Chain's Transaction Costs Through Logistics
}

Al Chen, (Email: al_chen@ncsu.edu), North Carolina State University

Karen Nunez, (Email: karen_nunez@ncsu.edu), North Carolina State University

\begin{abstract}
The bulk chemical industry primarily relies upon truck transportation. Truck transportation, although costly, has a high percentage of on-time deliveries. Cheaper alternative transportation modes are less preferred due to a lack of supply chain information. Traditionally, the lack of information about in-transit products leads to higher safety stock and inventory levels, which results in higher costs. Process mapping and activity-based cost analysis are used to identify cost drivers and highlight the areas of opportunity for improving bulk chemical supply chain management. The activity-based cost information was used to develop a logistics cost model specifically tailored to the bulk chemical industry. The activity-based logistics cost model was used to assess potential cost savings from integrating centralized supply chain management software (visibility solutions), into the bulk chemical supply chain. The results of our analysis support integrating visibility solution software into multi-modal transportation to improve bulk chemical supply chain management. Integration of visibility solutions enables suppliers to improve their ability to monitor and control their inventory throughout the supply chain, increase overall asset utilization, and reduce global supply chain costs.
\end{abstract}

\section{INTRODUCTION}

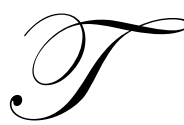

he competitive landscape of the $21^{\text {st }}$ century is one in which change is frequent, complex and challenging. Continuous increase in globalization of the world's markets is one of the most important of these changes. In response to the global economy, supply chain management (SCM) has been exploited by many firms as a competitive advantage in order to create value and earn above-average returns.

As the concept of supply chain management has evolved over the last decade, it becomes apparent that savings can be achieved by integrating management of the physical flow of materials and the information along the supply chain. The informational activities among the companies within a supply network allows for efficient integration. Stefan and Schneidereit (2002) suggest that the distribution of information in a supply network leads to transaction costs. These costs include contracting, distributing information, and coordinating transactions. The amount of these transaction costs in the supply network must be considered because the goal of supply chain management is to control costs and increase the value of the whole supply chain. It is expected that continued improvements in information technology can reduce these transaction costs. Using the bulk chemical industry logistics data, we demonstrate that supply chain management software facilitates information distribution and coordination, and results in reduced transaction costs in the supply network.

\section{BULK CHEMICAL INDUSTRY - AN INTRODUCTION}

The bulk chemical industry is characterized by low inventory costs and high transportation costs. The average bulk chemical costs approximately $\$ 0.50$ per pound, but the cost range is $\$ 0.10$ to $\$ 1.40$ per pound. The cost of transportation depends on the transportation mode used. The typical Product Cycle Time, which includes both internal production processes and door-to-door delivery to an "average" customer, is approximately 25 days. The industry is plagued by problems such as a low asset utilization rate - typically around 50\%, and low inventory turns. 
Currently, the preferred delivery method in the industry is via truck, which has a high percentage of on-time deliveries. However, truck transportation of bulk chemicals is the most expensive delivery mode. Rail transportation, which is a much cheaper alternative, is less preferred by most chemical companies because of the lack of information available about the status of shipments, and because of the relatively poor on-time delivery performance compared to trucks. The lack of information about the status of shipments leads to an increase in safety stock and inventory levels. Higher safety stock and inventory levels result in higher costs. Centralized supply chain management software would increase the level of information available and lead to reductions in safety stock and inventory levels.

The remainder of this paper is organized as follows. First, the key issues and developments in the chemical industry supply chain are discussed and the chemical industry's complex logistical process is described and mapped. Second, visibility solutions are introduced to demonstrate their ability to manage supply chain activities and create value by improving customer satisfaction. Third, an activity-based logistics cost model is used to assess potential cost savings from integrating visibility solutions in the chemical supply chain. The final section contains the concluding remarks.

\section{BULK CHEMICAL LOGISTICS}

Based on the results of an industry survey ${ }^{1}$, there are three different modes of transporting bulk chemicals that will be analyzed:(1) an all-truck Scenario, (2) an all-rail Scenario, and (3) a multi-modal service scenario which combines both truck and Rail. An explanation of the three modes, process maps, and the activities and costs associated with each mode are described below.

\section{All-Truck Scenario}

In this scenario, truck tankers are used to transport bulk chemicals from the supplier. Truck tanker capacity is approximately 35,500 pounds of chemicals. The advantage of using the all-truck mode is high on-time deliveries. This mode is ideal for short distances or for transporting relatively smaller quantities of shipments. However, the average transportation cost of $\$ 0.25$ per ton- mile associated with using truck tankers is extremely high compared to the other two transportation modes. This makes the all-truck mode $s$ an extremely expensive option when traveling long distances. The reliability offered by the truck mode drives an extensive use of truck tankers in this industry. Currently, 52.6\% of the dollar value of the bulk chemical transportation market is delivered by trucks ${ }^{2}$.

Three distinct steps are involved in the transportation of bulk chemicals using trucks. These steps are as follows: (1) Loading truck tankers at the suppliers' facilities, (2) The transportation of chemicals to the buyers' location, and (3) Unloading the chemicals into the buyers' storage facilities. Graph 1 shows the existing process map for the all-truck scenario graphically. The activities and costs associated with each step of the all-truck process are as follows.

\section{Activities At The Supplier's Facility:}

- $\quad$ Scheduling primarily involves determining the type and quantity of chemicals to be transported to a buyer, as well as preparing the invoices.

- $\quad$ Loading involves pumping the bulk chemicals into the truck tankers.

- $\quad$ Tracking represents the activities associated with following the transportation of the chemicals to ensure timely delivery, and to inform the buyer of any potential delays.

- $\quad$ Cleaning is required after each delivery, (if the tankers are used to transport different types of chemicals to different buyers) to prepare the tankers for the next delivery.

Assuming the truck tanker's volume is the order size, the cost driver for all the transportation activities at the supplier's facility should be the number of tankers. 


\section{Transportation Activities From Supplier To Buyer}

- $\quad$ Transporting: The total transportation cost of bulk chemicals positively correlates with the distance (number of miles) between the supplier and the buyer, and the total shipment size (i.e., the number of truck tankers). The in-transit inventory cost is driven by the number of days en-route from the supplier to the buyer.

\section{Activities At The Buyer's Facilities}

The activities at the buyer's facilities include order processing, unloading, tracking and warehousing. These activities are similar to the activities at the supplier's facility.

- $\quad$ Order processing primarily involves determining the type and quantity of chemicals to be ordered, as well as preparing the requisitions.

- $\quad$ Unloading involves pumping the bulk chemicals into the truck tankers.

- $\quad$ Tracking represents the activities associated with following the transportation of the chemicals to ensure timely delivery. The cost driver for order processing, unloading and tracking is the number of truck tankers.

- Warehousing: The bulk chemicals are stored for manufacturing and/or resale. The inventory cost is computed based on the average inventory and safety stock quantities.

\section{All-Rail Scenario}

Rail tankers, which have a capacity of 182,000 pounds, are ideal for transporting large quantities of chemicals over long distances. This is due to a low transportation cost of approximately $\$ 0.025$ per ton-mile associated with this mode. The rail transportation cost advantage, however, is offset by the disadvantage of a low percentage of on-time deliveries. 1995 data indicates that only $56 \%$ of rail car shipments were on-time ${ }^{3}$. Given such poor on-time delivery performance, rail transportation only accounts for $23.1 \%$ of the dollar value of the bulk chemical transportation market ${ }^{4}$.

The activities associated with rail transportation of chemicals and their cost drivers, are the same activities and drivers associated with the all-truck scenario. However, the all-rail activities require more time and different equipment, hence, the all-rail activity cost is different from the all-truck scenario. For example, the loading costs are higher in the all-rail scenario because it takes longer to load a rail tanker than to load a truck tanker. Each rail tanker is four times larger than a truck tanker. Graph 1 shows the existing process map for the all-rail scenario.

\section{Multi-Modal Scenario}

The multi-modal scenario combines truck and rail by using a combination of rail cars and truck tankers for the transportation of bulk chemicals from the supplier to the buyer. The multi-modal combination offers the dual advantages of low cost rail transportation and reliable truck transportation. The multi-modal solution is ideal for medium volume shipments.

The multi-modal scenario has the following steps: (1) The chemicals are initially loaded into the rail tankers at the supplier. (2) The rail tankers are transported via rail to a rail yard near the buyer's location. (3) At the rail yard, the chemicals are transloaded into trucks. (4) The chemicals are transported by truck to the buyer's location. (5) The chemicals are unloaded from the trucks when they arrive at the buyer's location. The "multi-modal" process map is also presented in Graph 1.

As indicated in Graph 1, there are more activities involved in the multi-modal scenario than the all-truck and all-rail scenarios because multi-modal service utilizes two transportation modes (truck and rail). The activities and cost drivers associated with multi-modal service include the same activities and drivers previously identified for both rail and truck transportation, as well as additional activities and drivers associated with transloading. Hence, multimodal service requires the same activities at the supplier's and buyer's facilities as the all-truck and all-rail modes. 
Furthermore, transloading requires additional receiving, shipping, handling, and tracking activities at the transloading rail yard.

Non-Value-Added Activities In The Existing Modes Of Chemical Transportation

All the activities described in all three transportation modes highlight many non-value-added activities being performed. Non-value-added activities are those that fail to simultaneously satisfy the following three criteria: (1) the activity produces a change of state, (2) the change of state was not achieved by preceding activities, and (3) the activity enables other activities to be performed. Additionally, inefficient performance of value-added activities leads to non-value-added costs (Hansen and Mowen, 2002). For example, buyers often contact the seller, and trucking/rail companies through telephone calls and fax messages for status updates concerning transit location, and the expected delivery time. In the case of poor delivery performance, it is estimated that excessive amounts of non-value-added activities will be generated. A logistics cost model that reports value- and non-valued added activities at a point in time, would allow managers to assess opportunities for improvement. More importantly, assessment and reporting of non-value-added activities and their costs facilitates evaluation of new technology such as visibility solutions that are designed to make logistics information available online on a real-time basis. Such innovative, web-based solutions are described below.

\section{LOGISTICS VISIBILITY SOLUTIONS}

Logistics visibility solutions are internet-based services that provide integration to, and data capture from logistic service providers (LSPs). The service providers cleanse, verify and analyze the data, and report on logistics activities to facilitate supply chain visibility. Logistics visibility solutions serve as a clearinghouse of logistics data to provide shippers with a global view of logistics activities regardless of the mode of transportation or service provider used $^{5}$. With real-time visibility of the products across all carriers (truck, rail, or barge) accessible via the web, this complete and synchronized information is critical for improving the daily tactical operations of supply chains. Traditionally, without visibility solutions companies typically carry excess inventories because of the lack of information about in-transit products. Visibility solutions provide necessary information that can lead to significant reductions in inventory levels.

In addition, visibility solutions serve as a clearinghouse of logistics data to provide shippers with a global view of logistics activities along the entire supply chain. Regardless of mode of transportation or service providers used, visibility solutions enable shipping companies to assess carrier pricing, carrier performance and to proactively manage logistic events. Managers can aggregate information across the supply chain to make strategic decisions on how to improve business processes with the added knowledge of interrelated logistical events. Many companies carry more inventories because of the risks associated with shipping products across borders, during holidays, and performance variability of logistics partners. Visibility solutions deliver real-time shipment visibility data needed for critical decisions on scheduling, shipping, and inventory allocation.

Key players in the visibility solutions market include BridgePoint, Celarix, Intellitrans, Joseph Transportation, and Transentric. Transentric ItemVision ${ }^{\mathrm{TM}}$ solution, for example, gives inter-enterprise visibility of inventory, equipment, and information. This solution collects and presents supply chain information that can be easily searched, shared, stored, accessed remotely, and linked to other relevant data and systems. The solution reconciles product names, unique identifiers, and units of measure from the customers and their trading partners automatically, which adds visibility, efficiency and reduces administrative costs.

In summary, visibility solutions allow companies to remove uncertainty within the supply chain, and therefore reduce inventory, labor, and equipment costs as described above. Section III includes cost analyses of the three bulk chemical transportation modes described earlier, as well as a cost analysis of a proposed transportation scenario enabled by visibility solutions. 


\section{SUPPLY CHAIN COST ANALYSES}

Traditional cost analysis identifies bulk chemical logistics costs in the following categories: inventory carrying costs, purchasing costs, and transportation costs. Traditional cost analysis also divides the costs into variable and fixed categories. However, using the detailed activity-based process maps described in Section I, logistics costs were identified in two additional categories: logistics activities and asset utilization. Furthermore, using the detailed activity-based process maps described in Section I, the underlying cost structure for each transportation mode was analyzed, and a logistics cost model specifically tailored to the bulk chemical industry was developed. The activitybased costing analysis results in a more detailed cost analysis then the traditional fixed versus variable analysis, and leads to a more comprehensive logistics cost model. Table 1 contains an example of the logistics cost model. The logistics cost model was used to evaluate a proposed transportation solution that integrates visibility solutions in the supply chain. Logistics Cost Comparisons

The three commonly used means of transportation (truck, rail, and multi-modal) require very specific handling processes for bulk chemicals, and therefore require different types of logistical activities. Since multi-modal involves both truck and rail tankers, it involves more activities than the all-truck and all-rail transportation modes. In the bulk chemical industry, chemical suppliers often own the assets that are used to transport their products. These assets include the rail cars and truck tankers that physically hold / store the chemicals. Rail tankers have a fourtruckload capacity but require a $\$ 90,000$ investment per tanker. Truck tankers only cost $\$ 25,000$ each, but have a much higher turnover rate than rail tankers. Because the chemical suppliers own these assets, the suppliers have a vested interest in increasing asset utilization (such as increasing turns and economic life), as well as decreasing the investment costs.

Most chemical companies use trucking and rail as their primary means of transportation. Using the process maps discussed previously, a bulk chemical logistics cost calculator was utilized to facilitate cost analysis and to determine the cost differentials of the following scenarios:

- $\quad$ All-truck transportation

- $\quad$ All-rail transportation

- $\quad$ Multi-modal transportation supported by visibility solutions

Multiple simulations were performed for each of the transportation scenarios listed above. The key parameters included product demand, product cost, transportation distance, and distance from the transloading yard to the customer. Table 1 highlights the costs that were included in the cost analysis.

The simulation results from the three scenarios indicate:

- Transportation is the leading cost driver in all situations, accounting for $90 \%$ of the cost in the all-trucking models.

- Inventory Cost is minimal, comprising approximately $1 \%-11 \%$ of the total cost. This is due to the low value of bulk chemical inventory and the manufacturing processes used by most chemical companies.

- Using extreme values as inputs to the logistics cost model, total transportation distance had the most significant impact on the total cost and the potential cost savings from using visibility solutions. Even in our scenarios, the shortest distance of 300 miles continued to provide a savings when using visibility solutions.

- $\quad$ Through multiple trials, it was determined that at approximately 150 miles of transit, the total cost of the alltruck scenario and the multi-modal/visibility solution are equal.

\section{Implications}

The results of this study indicate that the use of multi-modal transportation with logistics visibility solutions will assist bulk chemical suppliers and lead to an increase in asset utilization. Specifically, visibility solutions allow suppliers to have far greater and more reliable information that enables them to monitor and control the inventory and equipment throughout the supply chain. Visibility solutions allow suppliers to have real-time location information on 
their inventory and equipment, allowing them to quickly and easily determine the most cost-effective asset to use in fulfilling an order. Through this capability, the suppliers can use the shortest path logistics rationale, thereby reducing total transportation miles and transportation costs. Furthermore, suppliers with greater information on asset location and demand patterns have an increased ability to re-position inventory and equipment to areas where they are most needed. Visibility solutions also contribute to effective warehousing and reporting of data related to inventory over time. By tracking the inventory and asset usage over time, visibility solutions enable chemical suppliers to use a firstin, first-out method for turning assets. A first-in, first-out method leads to improved management of physical wear and tear across the asset-base. Because suppliers are better able to reuse equipment with identical chemicals when they have the ability to accurately track inventory and equipment. Re-using railcars and tankers with identical chemicals reduces cleaning costs and asset downtime due to cleaning.

In summary, the activity-based cost model suggests improvements through integration of multi-modal transportation and visibility solutions software. This study demonstrates that the bulk chemical supply chain's transaction costs can be significantly reduced with centralized supply chain management software. Visibility solutions can effectively reduce transaction costs related to information, communication, and coordination issues in the bulk chemical logistics process.

\section{CONCLUSIONS}

This study focuses on how an organization can create and utilize activity-based costing and management information across the supply chain. The bulk chemical logistics process requires implementation of synchronized activities that span multiple locations, involves multiple individuals and operating units, and often times spans multiple geographies and organizations. Activity analysis was used to map alternative logistics options and provide a bill of activities for specific transportation methods, including activity drivers and the amount of each activity expected to be consumed. Activity-based costing was used to assign costs to various transportation methods by tracing costs from activities to logistics processes. Activity-based costing and management were used to highlight the non-value added activities associated with the commonly used bulk chemical transportation modes. The current transportation modes have inherent weaknesses due to a lack of visibility of products across the supply chain. As a result of the lack of visibility, the bulk chemical industry relies to a large extent on truck tankers to transport bulk chemicals from the supplier to the buyer. Truck tankers are reliable and have a large proportion of on-time deliveries; however, the cost is extremely high compared to other transportation modes. Rail tankers have larger capacities and are a lower cost option, but have poor on-time delivery performance. Multi-modal transport combines truck and rail transport, resulting in cost improvements versus truck transportation and reliability improvements versus rail transportation, however, this method also lacks visibility of products across the supply chain.

The activity-based process maps identified areas of opportunity and highlighted the need for visibility solutions to reduce the non-value added activities in bulk chemical transportation. Most importantly, the process maps were integral in the development of a logistics cost model. The logistics cost model provided simulated results with process improvements that were generated from integration of visibility solutions. Visibility solutions allow suppliers to have real-time information and to quickly and easily determine the most cost-effective asset to use in fulfilling an order. As a result, suppliers improve their ability to monitor and control the location and usage of their inventory and equipment, increase overall asset utilization, and reduce global supply chain costs.

\section{REFERENCES}

1. $\quad$ Ballout, R. H., Business Logistics Management, $4^{\text {th }}$ Edition, Prentice-Hall Inc., 1999.

2. $\quad$ Bradley, P., How far can you see? Logistics Management, September 1, 2002.

3. Bragg, S. M., Accounting Best Practices, $2^{\text {nd }}$ Edition, John Wiley \& Sons, Inc., 2001.

4. Brewer, P. C. and T. W. Speh, Using the Balanced Scorecard to Measure Supply Chain Performance, Journal of Business Logistics, Vol.21, No. 1, 2000, pp.75-93.

5. $\quad$ Brimson, J. A., Activity Accounting, John Wiley \& Sons, Inc., 1991.

6. Challener C., E-Logistics and E-Transportation Log Into the Chemical Space, Chemical Market Reporter, November 19, 2001. 
7. Chen, J., Achieving Maximum Supply Chain Efficiency, IIE Solutions, Vol. 29, Issue 6, June 1997, pp.3035 .

8. Foster, T. A., Time to Learn the ABC's of Logistics, Logistics Management and Distribution Report, February 1999, pp.67-70.

9. Gooley, T. B., Finding the Hidden Cost of Logistics, Traffic Management, March 1995, pp. 47-53.

10. Gunasekaran, A., Marri, H. B., and R. J. Grieve, Justification and Implementation of Activity-Based Costing in Small and Medium-Sized Enterprises, Logistics Information Management, 1999, pp.386-394.

11. Hansen, D. R. and M. M. Mowen, Cost Managemen: Accounting and Control, $4^{\text {th }}$ Edition, 2002.

12. Lin B., Collins J., and R. K. Su, Supply Chain Costing: An Activity-Based Perspective, International Journal of Physical Distribution \& Logistics Management, Vol. 31, No. 10, 2001, pp. 702-713.

13. Logan, H. R., Jr., Controlling the Uncontrollabe, Strategic Finance, April 2001, pp. 56-61.

14. Mentzer J. T. and B. P. Konrad, An Efficiency/Effectiveness Approach to Logistics Performance Analysis, Journal of Business Logistics, Vol. 12, No. 1, 1991.

15. Richardson, H. L., The New Shape of ABC, Transportation and Distribution, May 2000, pp. 111-116.

16. Schroeder, R. G., Contemporary Concepts and Cases - Operations Management, McGraw-Hill, 2000. Thayer, A.M., Supply-Chain Management, C\&EN, January 5, 1998.

17. U.S. Department of Transportation, Commodity Flow Survey, 1997

18. Vo $\beta$, S. and G. Schneidereit, Interdpendencies between Supply Contracts and Transaction Costs, Cost Management in Supply Chain, Ed. Seuring S. and M. Goldbach, Heidelberg; New York: Physica-Verl., 2002. pp. 253-272.

\section{ENDNOTES}

1. United States Department of Transportation and United States Department of Commerce. 1997 Economic Census: Transportation: 1997 Commodity Flow Survey. Washington. Bureau of Transportation Statistics and U.S. Census Bureau, 1999.

2. IBID.

3. $\quad$ Statistical Appendix to Amtrak FY2000 Annual Report.

4. United States Department of Transportation and United States Department of Commerce. 1997 Economic Census: Transportation: 1997 Commodity Flow Survey. Washington. Bureau of Transportation Statistics and U.S. Census Bureau, 1999.

5. Logistics visibility solutions provide users with automated visibility that normally includes: purchase orders, purchase order line items, containers, shipments, documents, real-time, user-defined alerts for out of tolerance conditions in the supply chain, exception reports, performance evaluation on supply chain partners. 
Graph 1: Bulk Chemical Logistics Processes

\section{MAP TRUCKING / RAIL PROCESSES}
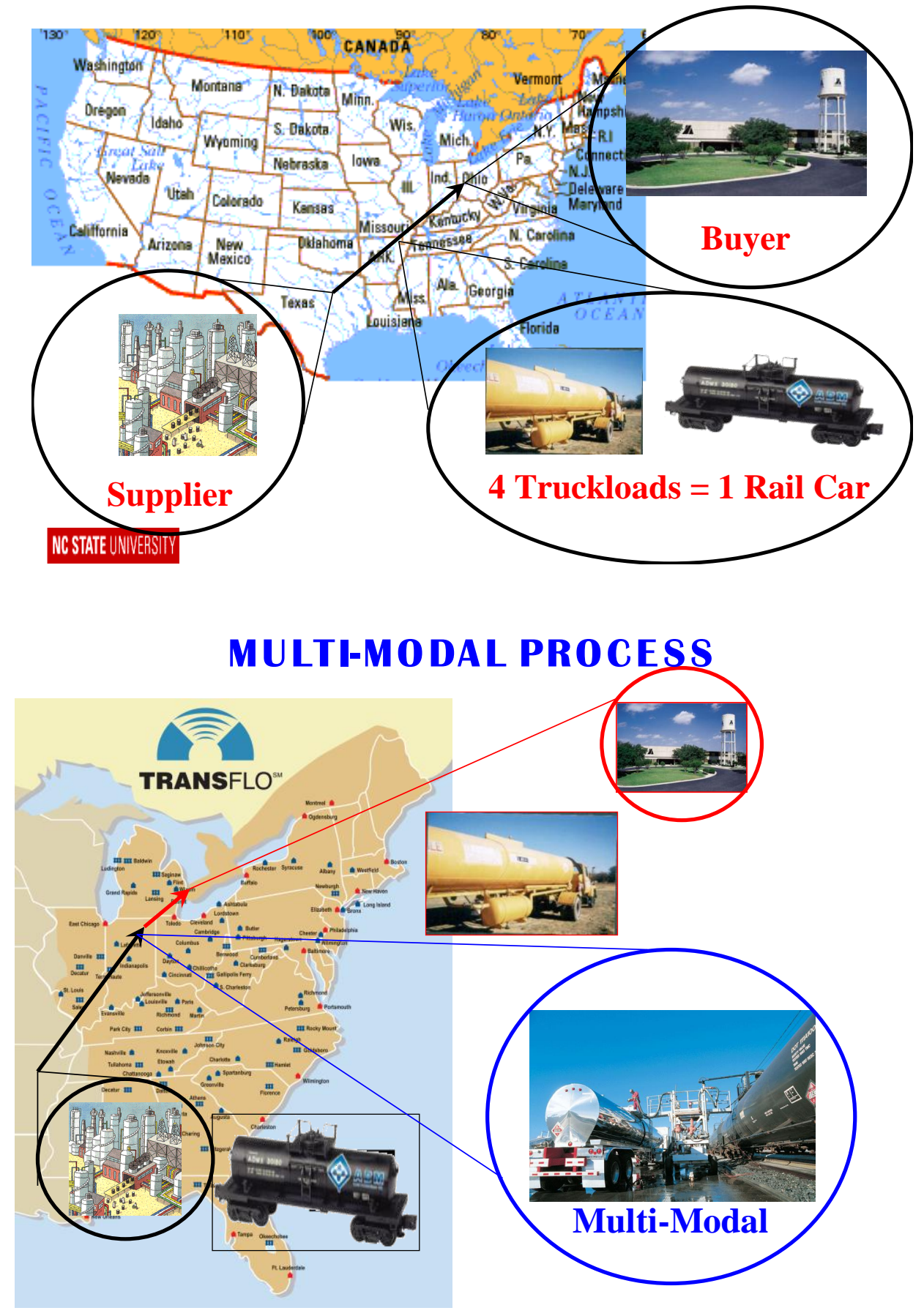
Table 1: Bulk Chemical Logistics Cost Calculator

\begin{tabular}{|c|c|c|c|}
\hline Supply Chain Costs & & & \\
\hline \multicolumn{2}{|l|}{ Data Input Summary } & & \\
\hline Annual Demand, pounds & $10,000,000$ & & \\
\hline Cost per lb & $\$ 0.50$ & & \\
\hline Carrying Cost Rate & $22.5 \%$ & & \\
\hline Trucking Cost (\$/ton-mile) & $\$ 0.250$ & & \\
\hline Trucking Load (pounds) & 45,500 & & \\
\hline Rail Cost (\$/ton-mile) & $\$ 0.025$ & & \\
\hline Rail Load (pounds) & 182,000 & & \\
\hline Miles (Supplier to Buyer) & 1,000 & & \\
\hline Miles (Supplier to Transflo) & 900 & & \\
\hline Truck Transit Time (days) & 6.9 & & \\
\hline Rail Transit Time (days) & 21.5 & & \\
\hline Miles (Transloading to Buyer) & 100 & & \\
\hline Transloading Truck Transit Time (days) & 5.6 & & \\
\hline Desired Customer Service Level & $95.0 \%$ & & \\
\hline z-Factor & 1.7 & & \\
\hline Std. Dev. Lead Time (Rail) & 3.99 & & \\
\hline Std. Dev. Lead Time (Trucking) & 1.24 & & \\
\hline \multirow[t]{2}{*}{ Std. Dev. Lead Time (Transloading Truck) } & 1.20 & & \\
\hline & Truck & Rail & Multi-Modal w/ Visibility \\
\hline Number of Orders / Shipments & 220 & 55 & 55 \\
\hline Transportation Costs & $\$ 1,251,250$ & $\$ 125,125$ & $\$ 250,250$ \\
\hline In-Transit Inventory & 189,041 & 589,041 & 742,466 \\
\hline In-Transit Inventory Cost & $\$ 21,267$ & $\$ 66,267$ & $\$ 83,527$ \\
\hline Buyer Inventory & 22,750 & 91,000 & 22,750 \\
\hline Buyer Safety Stock & 56,264 & 180,434 & 43,459 \\
\hline Buyer Inventory with Safety Stock & 79,014 & 271,434 & 66,209 \\
\hline Buyer Inventory Cost & $\$ 8,889$ & $\$ 30,536$ & $\$ 7,449$ \\
\hline Vendor Managed Inventory (VMI) & 0 & 0 & 91,000 \\
\hline VMI Safety Stock & 0 & 0 & 148,721 \\
\hline VMI Cost & $\$ 0$ & $\$ 0$ & $\$ 26,969$ \\
\hline Total Inventory & 268,055 & 860,475 & $1,048,396$ \\
\hline Total Inventory Cost & $\$ 30,156$ & $\$ 96,803$ & $\$ 117,945$ \\
\hline Carrying Cost & $\$ 17,622$ & $\$ 14,306$ & $\$ 24,775$ \\
\hline Ordering Cost & $\$ 2,244$ & $\$ 660$ & $\$ 604$ \\
\hline Customer Service Cost & $\$ 9,900$ & $\$ 14,850$ & $\$ 10,181$ \\
\hline Cleaning Cost & $\$ 59,048$ & $\$ 62,153$ & $\$ 90,901$ \\
\hline Asset Cost & $\$ 16,667$ & $\$ 48,000$ & $\$ 61,333$ \\
\hline Transloading Rail Car Storage Costs & $\$ 0$ & $\$ 0$ & $\$ 73,000$ \\
\hline Total Cost & $\$ 1,386,887$ & $\$ 361,897$ & $\$ 628,988$ \\
\hline
\end{tabular}


NOTES 